6

\title{
An Economic Assessment of European Commission Merger Control: 1958-2007
}

Bruce Lyons

\subsection{Introduction}

Mergers are a major means of restructuring-potentially allowing a more efficient allocation of resources as market conditions and firm-specific capabilities change over time. They provide a swift way to experiment with new ideas when the transaction costs of coordination, incentives, and exchanging ideas are expected to be lower within an organization than when using market transactions. This can enhance the efficiency of the merging firms, leading to increased competition, a spur to rivals, and improved competitiveness on the world stage. Potentially, both consumers and producers can gain from mergers.

However, mergers may also dampen the competitive process, by reducing the number of effective competitors, by softening competition, by impeding entry, and by reducing the incentives to innovate. This can harm both domestic consumers and international competitiveness. Effective merger regulation is the essential ex ante means of filtering merger proposals so that efficient ones are allowed while anticompetitive ones are not.

The Commission's jurisdiction for merger control includes only firms with a fairly large turnover and which have at least one-third of European sales outside a single Member State. Ninety per cent of such merger proposals falling within the Commission's scrutiny are allowed without any conditions. Headlines are made when a merger is prohibited, but this has happened only twenty times in seventeen years, during which time over 3,500 mergers have been appraised. Clearances subject to conditions (that is, remedies) happen over ten times as frequently as prohibitions, so the overall intervention rate since 1990 has been 7.5 per cent. $^{2}$ 
This is only the tip of the iceberg. Merger control is a powerful signal to firms contemplating mergers and they modify their proposals in anticipation of the merger regime. This is why the underlying logic for each intervention is so important. It is also why there are so few 'slam dunk' prohibitions. Merger control is so difficult because, in the presence of an effective regime and given compliance costs to the firms, only the beneficial or marginal mergers would be proposed. This means that, in an effective regime, all cases other than obvious clearances are likely to be difficult.

Seven-eighths of an iceberg is unseen below water. How many inappropriate mergers does European merger regulation deter? I am unaware of any EU-level evidence but a recent UK estimate (Deloitte 2007) surveyed over 200 senior competition lawyers and over 200 firms. Following external legal advice, five mergers were abandoned or modified for every merger that was blocked or modified by the UK competition authorities. ${ }^{3}$ However, external legal advice was taken in only 25 per cent of cases where firms modified or abandoned mergers on anticipated competition grounds, so the five-to-one ratio is an underestimate. ${ }^{4}$ It is likely, then, that there is at least as much 'below-thewater' or 'deterrence' effect for the ECMR as there is for an iceberg. This deterrence may be either positive or negative. Positive deterrence is where anticompetitive mergers are modified or abandoned, or alternative merger partners are found. Negative deterrence is where efficient mergers are abandoned or made less effective by modification or choice of a less suitable partner. More positive and less negative deterrence can simultaneously be achieved only by applying a clear 'economic effects' approach to merger appraisal. ${ }^{5}$ And, to spread the message, it is necessary to signal this approach in clearly argued decisions as well as in broad messages contained in guidelines and speeches.

One of my themes in this chapter is that over the last fifty years competition economics has been evolving as a discipline and, more recently, there has been a constructive interaction with the law. Law and economics are beginning to learn from each other. In section 6.2. I sketch the development of competition economics as a background to legal developments in European merger control. One of the lessons I draw is that the economics has been continuously developing over the last fifty years and it is sensible to bear this in mind when evaluating policy. ${ }^{6}$ A further section ('Trends in merger activity') provides some additional background from the perspective of shareholder returns and merger waves during the period. Section 6.3. picks up on the three key economic areas of merger appraisal: non-coordinated effects in horizontal mergers; coordinated effects in horizontal mergers; and non-horizontal mergers. These are ranked in decreasing order of the difficulty of economic analysis. A further section ('Merger interventions and remedies') considers the crucial and, until recently, under-researched area of the appropriateness of the remedies applied to mergers that have been found to be anticompetitive. 
Competition Policy in the EU

Commission practice is evaluated in each of these areas throughout section 6.3. In section 6.4. I turn to a broader statistical evaluation of the efficiency of DG Comp's merger regulation, in particular drawing on some simple ideas from bargaining theory, before concluding briefly in section 6.5 .

\subsection{Historical Context}

\subsubsection{A brief history of competition economics}

It is relatively easy for an economist to criticize particular merger decisions. We can dip into to our magnificent theoretical and econometric toolboxes to pull out the latest research technology and it is not hard to find a lack of sophistication of the practitioner's old-fashioned hammer. That is sometimes fair criticism but it can also be unfair because many of our new tools are very new and some are relatively untested for policy applications The purpose of this section is to place the evaluation of European Union merger policy in the context of the development of economic ideas. The intention is to provide a more even-handed critique of policy and practice by acknowledging some gaps in the academic literature.

The branch of economics that provides the foundations for competition policy is known as 'industrial economics' or 'industrial organization'. In the formative years before the 1957 Treaty, there were many different national traditions in the field, not all of which were founded in the microeconomics of individual markets. For example, the German approach was heavily influenced by 'Ordoliberalism'. Founded in the disasters of the first half of the last century which culminated in an unholy alliance between Nazism and cartels, Ordoliberalism saw competition policy as essential to protecting individual freedom, with clear and strong legal rules necessary to provide a bulwark against political and corporate repression. ${ }^{7}$ In contrast, Anglo-Saxon economics focused on microeconomic efficiency. There were many anecdotal case studies of how competition operated. A classic example from the time was a major US work providing the first systematic treatment of barriers to entry (Bain 1956). There was no internationally dominant advanced textbook on the subject. ${ }^{8}$

During the 1960s and 70s, US economists developed a theoretical framework known as Structure-Conduct-Performance (SCP) which drew a link between market structure (for example, concentration, entry barriers), the way firms behaved (for example, collusion versus more competitive pricing), and performance (for example, efficiency of production, consumer welfare). Case studies were supplemented by econometrics as computers became available to academics, with the emphasis of looking for broad trends across industries to support the SCP approach. This approach was brilliantly brought together 
in Scherer 1970, an advanced textbook that also had some influence on this side of the Atlantic. However, it was based essentially on US research and evidence. Also, some of the theoretical foundations of SCP were a little ad hoc by modern standards of rigour. The approach was also challenged by a strongly non-interventionist 'Chicago School' of thought which became highly influential, not least because it worked so closely at the interface between law and economics (for example, Posner 1976 and Bork 1978-the writers of both becoming judges). Entering the 1980s, however, industrial economics was about to change and leave its fragmented schools of thought substantially behind.

In the period up to the introduction of the European Commission merger regulation (ECMR) in 1989, but too novel to influence it, there were two revolutions emerging in industrial economics. First, 'game theory' was finally providing a unifying framework for investigating strategic interaction between firms. Since the deepest idea comes straight from Cournot 1838, it is not clear why it took so long for game theory to come centre stage, but that is not a question to dwell on here. Game theory proved a fantastically flexible tool for testing whether some of the claims from SCP were consistent with rational behaviour and for investigating new ideas. Many of the SCP insights were confirmed, but the sensitivity of some results to apparently minor assumptions made industrial economists think very hard about the foundations of how firms compete. An interesting feature of this development was that European economists (often working in US universities) were at least as important to developing these ideas as were Americans. Game theory was a unifying idea in more ways than one. The early fruits of this approach were brought together in a remarkable text by Tirole (1988), which has since served generations of graduate students on both sides of the Atlantic. From now on, the intellectual story is largely one of transatlantic consensus. ${ }^{9}$

These terse academic ideas were not yet ready to be influential for merger policy. There was much too much of an 'anything can happen' about them, and not enough attention to real policy issues. Furthermore, there was little in the way of empirical foundation. This was just around the corner and developed through the 1990s. New datasets on specific markets combined with rigorous theoretical models and powerful computers to provide new ways to understand competition in actual markets. In the context of merger appraisal, this ability to model how a market currently competes appeared to be just one step away from the holy grail of predicting how the market could be expected to operate post merger.

Moving into the current century, there is an increasing interaction between policy cases and academic industrial economics. Economists realize the value of real cases not least as a way of gaining understanding of the business practices that matter. It is no longer good enough to develop a toolkit and tell practitioners to use it. The process is more interactive. Real policy issues, 
Competition Policy in the EU

including merger cases, are stimulating theoretical developments within a common and fairly stable framework of analysis. A new sub-discipline of competition economics, much more nuanced to legal ideas and practical policy, has emerged.

In the context of this history of fast-changing ideas, the fact that practical merger control in Europe seriously engages with new research is something to be applauded. However, this comes with a health warning. The new toolkit is powerful and convincing because it is sensitive and subtle. This means that a strong training is necessary to use it properly. This is not to say that it is beyond the comprehension of a good competition lawyer or the firms themselves. Good economic analysis is sensible and intuitive once properly explained. But, it is to say that a strong training is necessary to understand when a superficially sensible theory may be profoundly misleading. Consequently, there is a danger that ideas are applied inappropriately. ${ }^{10}$ Some of the fault lies with economists (not economics) - for example, too many economists are too ready to identify an 'equilibrium' outcome without spelling out the essential elements underpinning that equilibrium (for example, empirically verifiable assumptions), let alone the dynamics of getting there. This is an issue on which economics can learn from the law. The legal approach of making an argument in bite-sized steps is important for confirming whether each step applies to the case in hand. This has been recognized by the CFI (for example, Airtours/First Choice). Where this decomposition of steps is not possible, as is the case for some highly sophisticated simulation models, economists need to be very careful to explain whatever steps they can, to be honest about the limitations of their tools and to be particularly cautious in interpreting their conclusions. It is unwise to rely on analysis that is not explained intuitively step by step.

Next, I turn to what was happening to merger regulation in Europe during the same fifty years that competition economics was evolving as a discipline.

\subsubsection{Evolution of EC merger control}

\section{7-89: PRE-ECMR}

The Treaty of Rome made no explicit provision for merger control. Nevertheless, both Articles 81 and 82 (originally 85 and 86 respectively) were applied to mergers in a limited way. The legal basis under Article 82 was established by the Court in Continental Can (1973) and this seems to have allowed some degree of influence by the Commission over potentially very unattractive mergers. However, it could only be used against a firm that was already considered dominant, and could not prevent the creation of a dominant position (Whish 2003). The Commission also tried to apply Article 81 to mergers, and in BAT (1987) the Court found that the acquisition of a minority shareholding might be an infringement if it brought anticompetitive influence. It was only in December 
1989 that ECMR brought explicit merger control at the European level, and the focus of this chapter is on what has happened since.

Nevertheless, it is worth recalling the combination of economic and political factors that created the climate to introduce explicit merger control at that time. Insiders in the Commission (DG IV) had wanted the power to control mergers for some time, but faced resistance from firms arguing that size was necessary to compete against America and Japan. National competition authorities were also anxious to preserve their competences. This stalemate was part of a much wider languishing of European common policy over the previous decade. However, things were about to change. DG IV under the leadership of Irish commissioner Peter Sutherland was able to capitalize on the opportunity created by a number of factors in the mid-1980s. A remarkable and unlikely combination of Commission leadership (Delors and Cockfield) with the confluence of domestic agendas of the most powerful heads of state at the time ${ }^{11}$ resulted in the Single European Act of 1985.

This aimed to create a single European market by the end of 1992. It did not introduce merger regulation, but it reinvigorated the idea of common policy and it put the benefits of competition centre stage. The economics of market structure suggests that the number of firms that can survive in a market depends on the size of that market and the toughness of competition. In particular, a larger market supports a less than proportionately greater number of firms because prices are driven closer to marginal costs. The process of integration must consequently be expected to see a period of exit or consolidation between firms. In markets where the geographic market at which competition was anticipated to take place rose from the national to the European level, concentration would rise. This is exactly what we observed (Lyons 2001). Associated with this, the late 1980s saw a significant merger wave (though nowhere near as big as the 1990s wave) and the expectation was that this would grow as firms prepared for the single market. ${ }^{12}$ It was important to control this process to ensure it did not go too far.

Finally, firms themselves were beginning to see the benefits of Europeanlevel merger control. They were increasingly worried by the prospect of double jeopardy in multiple filings if they wanted to complete a cross-border merger. Their advisers were also aware of the recent ECJ decision over BAT, which opened up the horrifying possibility that a merger might at some future date be declared void because it breached Article 81 .

\section{9-2002: ESTABLISHING THE NEW ECMR}

\section{ORGANIZATIONAL ISSUES}

The new ECMR was operated by a specialist unit within the then DG IV-the Merger Task Force (MTF). It had to work to a very precise and tight timetable with time limits both for its initial Phase I scrutiny (basically one month) and 
Competition Policy in the EU

for its more extended Phase II investigations (a further four months). There were only around fifty-five cases per annum until 1993, after which there was an unprecedented merger boom reaching around 330 cases annually at the turn of the century. The relatively quiet early years gave the opportunity to develop processes and an esprit de corps. Nevertheless, by necessity, cases had to be dealt with rapidly. It is perhaps not surprising that there were some significant inconsistencies and elements of poor economic analysis in the early years (Neven, Nuttall, and Seabright 1993). However, a combination of case overload and possible complacency was to mean that bad practice was not weeded out (see Kühn 2005, for examples), resulting in the reversals of 2002. It also became apparent that the tight timetable left too little time to consider sensible, effective remedies short of prohibition.

There are four distinct stages in the application of merger policy: decision to clear (possibly subject to agreed remedies) or to investigate in depth (Phase I); in-depth investigation (Phase II); decision to clear, prohibit, or require remedies (formally taken by the full college of the European Commissioners); and possible appeal (CFI and ECJ). Since the full set of Commissioners is entirely non-specialist and all but one has their eyes fixed on their own portfolios, this leaves the Competition Commissioner in a potentially very powerful position. It is very hard for an outsider to judge how this power is wielded, but it must be difficult to push too far from the 'house' (that is, 'staff') opinion except in exceptional cases. Nevertheless, the Competition Commissioner has weekly meetings with DG Comp staff, at which his or her views on particular cases can be made clear, and other Directorates with sectoral expertise are widely consulted throughout the investigation, and can probably be influential. ${ }^{13}$

Leaving aside this limited amount of political influence, the process is such that the first three of the four stages identified above are all conducted by DG Comp (formerly known as DG IV), which is investigator, prosecutor, and jury. The dangers are compounded by the practice of the same teams taking cases from Phase I to Phase II, so any preconceptions or prejudices carry through. It almost invites an investigation team to get locked into a provisional judgment it had to make during the early weeks of Phase I. Human nature is that we prefer to prove ourselves right rather than wrong, so the temptation must be to spend Phase II trying to justify the Phase I decision to refer. Thus, it is crucial to have an effective appeal system if good economic analysis is to be sustained.

Unfortunately, the distance of the appeal provided only a limited constraint, at least before 2002. The parties to a merger can appeal to the CFI. A further appeal, limited to legal questions, may also be possible to the ECJ. Both are traditionally lengthy processes, and business realities mean that it is extremely difficult to resurrect a merger prohibition that has been overthrown on appeal. An important 2001 reform introduced the expedited procedure, particularly for merger appeals, in the CFI (with the intention of deciding on appeals within twelve months). However, accelerated appeals are not universally 
allowed and there can still be substantial delays. ${ }^{14}$ European merger control is very much more distant from the courts than is the US procedure, where the courts cast a continual shadow on the FTC or DoJ, even though the parties typically settle out of court. ${ }^{15}$ Both sides in the US system must continuously ask themselves: 'how would the courts interpret the evidence we are providing to support our arguments?'. In contrast to the USA, the court in Europe does not attempt fact finding. The question it asks is one of judicial review, so DG Comp must only ask itself: 'would the court find that we have failed to adopt the correct procedure in collecting evidence, and have we been sufficiently diligent in trying to interpret it?'. ${ }^{16}$ Despite a shot across the Commission's bow in Kali \& Salz (1998), where the Court called for closer examination of the merger, this does not seem to have had a major impact on reforming internal procedures.

One final element of procedure deserves honourable mention. A major advantage of the EU system is that reasoned (and relatively readable) decisions are published. In the US, because it is adversarial, far too much remains unpublished and there is no clearly argued case to review. As any academic knows, written publication is a major discipline for clear thinking, as well as for the dissemination of appropriate analysis. While this does not completely compensate for the lack of internal checks and balances, its value should not be underestimated.

\section{SUBSTANTIVE ISSUES}

A unique feature of the ECMR, by international comparisons, is that because of the 1957 Treaty, the Commission must be concerned with market integration. Even now, post introduction of the euro, economic integration is still very much less advanced in Europe than in the United States. Integration issues impinge on mergers in two principal ways. First, some national corporate governance rules impede the market for corporate control. Second, and most relevant to competition policy, the national application of merger control can potentially distort the market in much the same way as nationalistic state aids. The scope of the ECMR was intended to pick up any merger with a 'Community dimension', but there have been gaps. The commendable idea was to apply the principle of subsidiarity to mergers with operations predominantly in a single country. However, the combination of an absolute size threshold and a proportionate sales distribution across member states (The Commission does not have jurisdiction if less than one-third of turnover is outside the home market) was to cause significant problems in a very limited number of important cases. In particular, it leaves some very significant European mergers in the hands of national authorities who have revealed themselves to have more interest in 'national champions' than in preserving competition. Despite attempts at reform, this problem has endured and continues to undermine good merger regulation in a few important cases. ${ }^{17}$ 
Competition Policy in the EU

Another area of concern was the substantive test in the original ECMR (which has since been revised and improved). The original test by which mergers were to be appraised is provided by Article 2(3) of the ECMR (1989): 'A concentration [i.e. merger or acquisition] which creates or strengthens a dominant position as a result of which effective competition would be significantly impeded in the common market or in a substantial part of it shall be declared incompatible with the common market'. This is commonly referred to as the dominance test (DT). The primary importance of establishing 'dominance' is that it encouraged a formalistic approach based on market share. The DT contrasts with the United States' 'substantial lessening of competition' (SLC) test, which is currently interpreted as 'whether the merger is likely to create or enhance market power or to facilitate its exercise' (US Merger Guidelines 1997). ${ }^{18}$ The semantic difference between the DT and the US SLC test may seem minor but in practice it did make a difference in giving too much weight to market shares, and so market structure, over economic effects. ${ }^{19}$

On its own, the DT was not a bar to good economic analysis. As I have argued in section 6.2.1., economic ideas were moving along at a rapid pace. How were economic ideas able to penetrate into the Commission? Economists were embedded in the case teams, but few had the PhD-level training in industrial organization that is necessary to check the quality of sophisticated economic analysis. There was little formal training in competition economics, and only a very informal academic advisory group (from around 1997). Meanwhile, both the Commission and merging parties were being offered a new weapon. External economic consultancies had first appeared in London during the mid-1980s and these were available to advise on merger control. The Commission began to use them for commissioned reports into various issues such as market definition and quantitative techniques. Merging parties began using them to hone their defence on particular mergers. By 1995, Neven estimates that the total amount of fees for the three largest competition consultancies was c.£2.5 million, including both EU and national advice. The Commission's market definition notice of 1997 was important in its explicit use of economic concepts and this appears to have been a trigger for the consultancies to grow. By 2004, turnover had grown nearly tenfold, with around 150 professional economists working in European consultancies-this is very many more than were working in the Commission. ${ }^{20}$ There was a clear imbalance of economic expertise and the Commission was struggling with the economic analysis.

THE 2002 APPEALS

The Commission suffered a series of high-profile reverses in the European CFI in the following judgments: ${ }^{21}$ 
- Airtours/First Choice: DG Comp did not conduct a sufficiently rigorous economic analysis of the incentives for and ability to coordinate behaviour as a consequence of the proposed merger. ${ }^{2} 2$

- Schneider/Legrand: DG Comp failed to take account of the different degree of competition in each of the national markets it identified, and did not provide Schneider with enough information to offer an appropriate remedy.

- Tetra Laval/Sidel: DG Comp should have: (a) taken account of the fact that its concern over leveraging market power between two otherwise separate markets would have required tactics that are illegal under Article 82; (b) provided a proper appraisal of behavioural commitments before resorting to its favourite structural remedy (divestiture); and (c) adopted a higher standard of proof. ${ }^{23}$

As can be seen, these appeals raised a range of concerns, including both inadequate economic analysis and procedural weaknesses. Such concerns have since been reinforced by a 2005 CFI judgment relating to a controversial 2001 decision:

- GE/Honeywell: although the prohibition decision was upheld due to a relatively minor horizontal part to DG Comp's case, the Court strongly condemned their analysis of conglomerate effects (i.e. the theory that the merger would result in exclusionary effects due to opportunities to bundle products). ${ }^{24}$

Table 6.1. provides some context for the way in which these Court landmark decisions related to the timing of Commission-led initiatives in merger policy. ${ }^{25}$

\section{3-7: REFORM}

It would be wrong to attribute all the reforms to the CFI reverses of 2002 . Indeed, the Green Paper on reform had been published in 2001. The truth is that the CFI hastened and sharpened the reforms, but change was already on the way. Ten new member states were due to join the European Union in May 2004 bringing a potentially large increase in caseload at the same time as a merger boom. Much of this caseload might relate to state aids and other areas, but there would also be merger concerns because of the multiplicity of national geographic markets until the new members on the perimeter of the European Union become more economically integrated. DG Comp needed more-efficient procedures to deal with this. It was also a fairly natural time to reflect on the ECMR, with an active Commissioner Monti and a significant amount of experience following the reviews of the first decade. It would have been surprising if change was not necessary. Possibly most important in the long run, however, was the economic analysis being used increasingly to inform competition decisions across the globe. It presented a serious challenge to integrate top class economic analysis centrally into merger appraisal. 
Competition Policy in the EU

Table 6.1. Soft law and precedent in EC merger control since 1989

\begin{tabular}{|c|c|c|c|}
\hline Date & Commissioner* & Commission led & Court landmarks ${ }^{+}$ \\
\hline 1989 & Sutherland & ECMR & \\
\hline 1990 & Brittan & & \\
\hline \multicolumn{4}{|l|}{1991} \\
\hline \multicolumn{4}{|l|}{1992} \\
\hline \multicolumn{4}{|l|}{1993} \\
\hline 1994 & Van Miert & Joint ventures & \\
\hline \multicolumn{4}{|l|}{1995} \\
\hline \multicolumn{4}{|l|}{1996} \\
\hline \multirow[t]{3}{*}{1997} & & Revisions to ECMR on full & \\
\hline & & $\begin{array}{l}\text { function joint ventures, Phase I } \\
\text { remedies and procedure. }\end{array}$ & \\
\hline & & $\begin{array}{l}\text { Relevant market notice; access } \\
\text { to file }\end{array}$ & \\
\hline 1998 & & & Kali \& Salz (ECJ) \\
\hline \multicolumn{4}{|l|}{1999} \\
\hline 2000 & Monti & $\begin{array}{l}\text { Simplified procedure for small, } \\
\text { low market share mergers }\end{array}$ & \\
\hline 2001 & & $\begin{array}{l}\text { Green Paper on ECMR reform; } \\
\text { Remedies notice; role of } \\
\text { hearing officer }\end{array}$ & CFI expedited procedure $(<1 \mathrm{yr})$ \\
\hline 2002 & & EU-US cooperation agreement & $\begin{array}{l}\text { Airtours/First Choice; } \\
\text { Schneider /Legrand; Tetra } \\
\text { Lavel/Sidel }\end{array}$ \\
\hline \multicolumn{4}{|l|}{2003} \\
\hline 2004 & & $\begin{array}{l}\text { Major revisions to ECMR (inc. } \\
\text { substantive test and } \\
\text { efficiencies). }\end{array}$ & \\
\hline & & $\begin{array}{l}\text { Horizontal guidelines; } \\
\text { procedural best practice } \\
\text { guidelines }\end{array}$ & \\
\hline
\end{tabular}

Some of the reforms were organizational or procedural. The MTF was dismembered and folded into other mainly sectoral units. Devil's advocate panels (known as 'a fresh pair of eyes') were introduced to provide an internal critique of the arguments provided by case teams. This does not eliminate the problem of a single case team taking the case from start to finish, but along with the chief economist's team, it was a step in the right direction. The merger appraisal timetable was extended to allow more time to develop remedies appropriate to the expected competitive harm.

Other reforms were targeted directly at developing better and more consistent economic analysis. First, the important new post of Chief Competition Economist (CCE) was created and filled by an independent-minded academic economist, Professor Lars-Hendrik Röller. He was provided with a small team of ten well-trained economists to help case teams with more technical economic analysis. It appears that the Chief Economist's Team (CET) has been broadly welcomed by case teams (not least for easing their workload) and has provided helpful advice, but it remains small and has duties wider than casework. ${ }^{26}$ In 
addition, the CCE acts as an independent adviser to the Commissioner with the power to offer 'final advice' also to the College of Commissioners immediately prior to a final decision. This is a potentially very powerful procedure in the event that the CCE disagrees with the case team and relevant senior officials in DG Comp. Second, horizontal merger guidelines were published, explaining the circumstances in which a merger might be expected to result in competitive harm. These provide an important discipline within the 'house', as well as providing external guidance and principles for positive deterrence. Last, but not least, there was a subtle change to the substantive test.

\section{THE NEW SIEC TEST}

The European Commission Green Paper (2001) reviewing the merger regulation spent only four pages of a fifty-eight-page document on substantive issues (the dominance test, merger-specific efficiencies, and simplified procedure), with the rest going into great detail on jurisdictional and procedural issues. But it turned out that the substantive issues were the most important for reform. In particular, the dominance test was replaced by a standard apparently much closer to the US SLC. The 'new' standard was that a merger should not be a 'significant impediment to effective competition'. ${ }^{27}$

Was it necessary to change the substantive test? The US experience possibly suggests not. The 1968 US guidelines state that 'the primary role of Section 7 enforcement is to preserve and promote market structures conducive to competition'. This sounds like a very structural interpretation of an SLC. But the major revision to the guidelines in 1982 is far more specifically economic effects based: 'mergers should not be permitted to create or enhance market power or to facilitate its exercise'. This wording has essentially survived in subsequent revisions. Now is not the place to try to explain the role of economic ideas in the evolution of US merger control, but the timescale of ideas between the 1914 Clayton Act and the 1982 revision is on a completely different scale to the time span between 1989 and 2002. The ECMR needed a more substantial kick than a set of guidelines. ${ }^{28}$

One interpretation of the DT is that it could be seen formally as establishing whether the competition authority was considering either an independent effect or a coordinated effect of the merger. The former would be traditional dominance by a single firm, and the latter would be a case of collective dominance. However, this fails to appreciate that a merger to create the second or third biggest firm may have unilateral as well as coordinated effects. In essence, there were two problems. ${ }^{29}$

First, the DT could be 'too harsh' on merging firms and that would create an efficient new enterprise with an incentive to cut price or improve quality to such an extent that this might make an existing rival unprofitable (or at least reduce its market share). This would 'create dominance' only by increasing 
Competition Policy in the EU

competition, but it still might fall foul of a crude interpretation of the DT because of the reduced number of competitors. This led to accusations that DG Comp was protecting competitors more than consumers in some cases (Neven, Nuttall, and Seabright 1993: ch. 3.5). While it is possible to imagine situations where the preservation of a less-efficient firm in the market might be desirable for long-term competition considerations, such situations are very exceptional and a competition authority should be made to justify such a judgment on competition grounds, and not on easy appeal to crude dominance.

Second, the DT could be 'too generous' to merging firms because of the double hurdle for the competition authorities. In particular, the DT could allow an undesirable merger that significantly impedes competition, but which does not meet the dominance criterion. The doctrine of collective dominance was sometimes tortured into filling the gap-for example, Airtours/First Choice (see sect. 6.3.2. below). ${ }^{30}$

The SIEC test was exactly the right change to make. It built on the existing test, and changes only what was necessary for a more efficient and effective system of merger control. It allowed the maximum use of good case law and signalled continuity, thus minimizing uncertainties during transition. It had the additional benefit that it is semantically almost indistinguishable from the SLC test and so contributed to an emerging world standard (see also Vickers 2004). Any transatlantic disputes over merger appraisal should no longer hide behind legal wording. I have already argued that the academic literature on competition economics has converged. Consequently, transatlantic disputes must be due to either a difference of issues that the merger raises in European as distinct from American markets or from mistakes by one side of the Atlantic in their economic analysis (or from national protectionism encroaching on the discretionary range of interpretation of a lessening of competition).

\subsubsection{Trends in Merger Activity}

There is no reliable data on trends in European mergers prior to the mid-1980s, but there appears to be no evidence of substantial activity on continental Europe from 1957 until this time. UK data do reveal a substantial peak in activity in the early 1970s. ${ }^{31}$ This happens to be the time that the UK joined the European Union, but this merger wave was probably more tied to the concurrent merger wave in the USA and, to an extent, a delayed effect of the 1956 Restrictive Trade Practices Act which outlawed cartel agreements. ${ }^{32}$

Two and a half genuinely European merger waves are discernable since the mid-1980s, and these also broadly coincide with peaks of M\&A activity in the USA. Mergers can be measured in different ways, but one set of figures suggests the 1980s European peak by value of deals was in 1989, having risen steadily from the mid-1980s. Measured by number of deals, the first peak was in 1991. 
Merger Control: 1958-2007

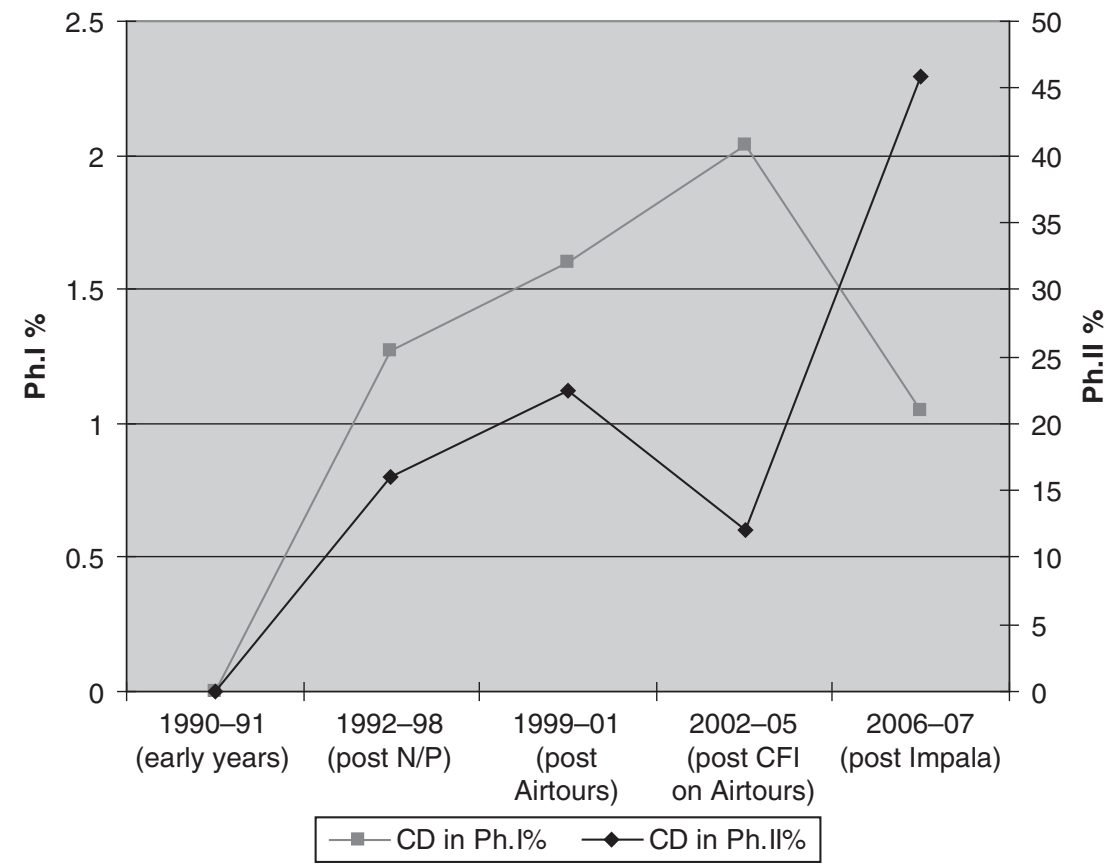

Figure 6.1. Trend incidence of coordinated effects analysis

This peak was exceeded by 1995 and increased rapidly until the turn of the century before falling away (see Martynova and Renneboog 2006a: Figs. 2.1 and 2.2). ${ }^{33}$ Our period ends with the beginning of a third wave in the mid2000s, starting around 2004.

In Figure 6.2., we measure activity relevant to merger control by the number of Phase I decisions. This measure combines a value effect (because of the notification threshold) with a numbers effect (since it is a simple count), along with a requirement for the mergers to have an effect on trade between Member States. The pattern broadly reflects other measures of M\&A activity, though it demonstrates a much stronger upward trend overlaying the waves of activity. For example, the number of deals in Martynova and Renneboog 2008a roughly doubles between the 1991 and 2000 peaks, while the number of Commission decisions rises sixfold.

Martynova and Renneboog 2008b characterize this period of European mergers as increasingly involving cross-border activity and mainly between firms in the same broad industry. There were some huge equity-funded deals in the turn of the century peak compared with more buyouts in the earlier period and private equity in the most recent period. Each merger wave has ended with a stock market crash. 
Competition Policy in the EU

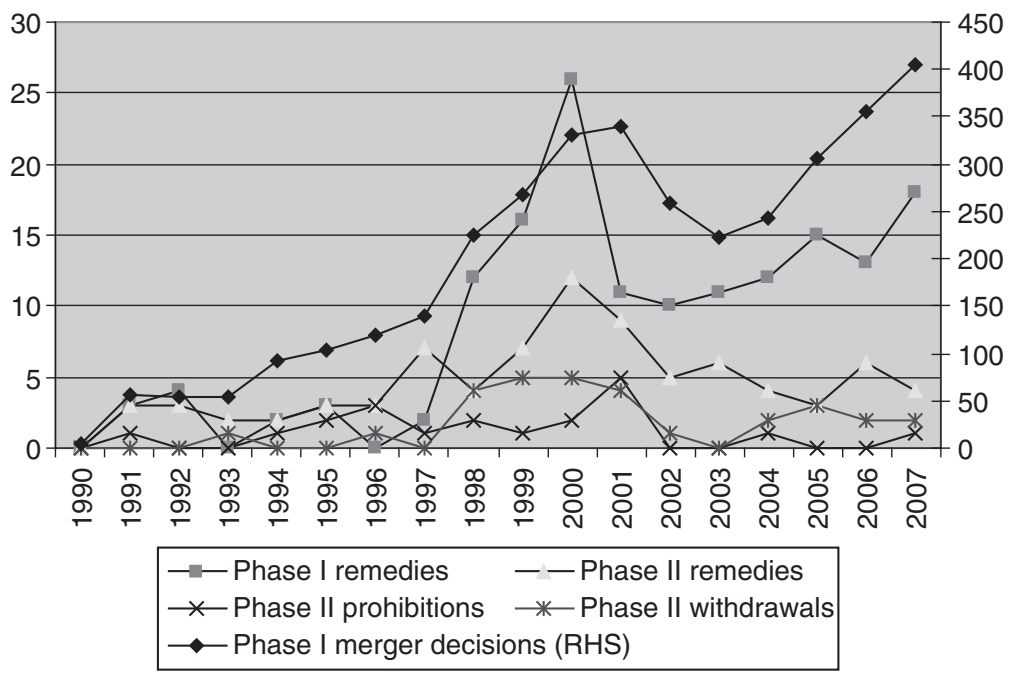

Figure 6.2. Merger and intervention trends

Even if not of direct relevance to merger control, it is interesting to consider the average private pay-off to mergers. There have been numerous event studies of stock market reactions to merger announcements. These are founded on the assumption of efficient markets. Event studies look at the few days around a merger announcement and usually separate the impact on the bidder from that of the target. Measured against market trends, they estimate cumulative abnormal returns, CARs, which can be attributed to the news of the merger. The CARs therefore reflect the capitalized market expectation of enhanced profitability due to the merger. This may be due either to enhanced efficiency or enhanced market power. Recent examples based mainly on the European turn of the century merger boom include Campa and Hernando 2004, Goergen and Renneboog 2004, and Martynova and Renneboog (2006a; 2008b). On average, these find an increase in CARs for the target in the order of 10-20 per cent, more or less zero for the acquirer, and around 1 per cent combined. However, studies looking at how stock market returns evolve over the following years are much more pessimistic. There has been less European research of this nature, and such studies inherently cannot look at the most recent period, but more studies find a negative impact than find a positive effect. A similarly pessimistic picture emerges from studies of post-merger operating performance (for example, profitability, growth). ${ }^{34}$

Overall, the financial markets continue to support merger activity which consequently continues with trend growth overlaying distinct merger waves. Event studies suggest most of any capitalized expected benefits are captured by the acquired firm's shareholders, but long-term studies suggests that 
anticipated benefits are not always achieved. ${ }^{35}$ From the perspective of merger control, however, none of this is particularly relevant. A competition authority is not a management consultancy. Its role is to ensure that mergers do not harm competition and consumers. Inasmuch as many mergers destroy value, shareholders and policy makers must develop appropriate corporate governance to look after the interests of the firms' owners and employees.

\subsection{Merger Appraisal and Interventions}

This part reviews EU merger appraisal according the relevant theory of harm. There are three broad categories. We have a very settled theory of non-coordinated effects with canonical models and clear predictions. This has allowed the development of quantitative techniques leading up to full simulation models. The unambiguous price- raising tendencies of horizontal mergers also focus attention on merger-specific efficiencies. The theory of coordinated effects is much newer and though it has rapidly achieved a consensus canonical model, there are still major gaps, not least its silence on how a particular equilibrium is achieved. The theory of non-horizontal effects is very delicate and often insecure, especially as applied to mergers. It should be treated with great caution, not least because rival firms have perverse incentives in lobbying the Commission. A fourth section appraises some aspects of the Commission's practice in merger remedies. ${ }^{36}$

\subsubsection{Non-coordinated (unilateral) effects}

\section{SIMULATION MODELLING}

Quantitative techniques are fundamental to unilateral effects horizontal merger appraisal. The crudest is simple market share analysis. At various times, the Commission has been accused of using a simple 40 per cent or 50 per cent rule on joint market share to find dominance. ${ }^{37}$ Although it has never been that simplistic, it can look that way especially when remedies are hastily agreed in Phase I in mergers with multiple market overlaps.

The Commission typically supplements joint market share with consideration of the market shares of leading rivals. The argument is that a large rival suggests a greater ability to compete against a newly merged firm with a large market share. This may be because it has low costs or a particularly attractive product offer. ${ }^{38}$ Beyond this, the Commission's analysis is far less systematic.

A big gap in Commission practice is that there is no systematic analysis of demand elasticities and cross-elasticities. ${ }^{39}$ In even the most basic economic models, the industry elasticity of demand is important in converting market 
Competition Policy in the EU

share into market power. With differentiated products, the cross-elasticities of demand are also important. Economic theory provides a framework for linking all these concepts, and econometrics provides a way of estimating the elasticities. Merger simulation blends these together in order to ask the central 'what if?' question: what would happen to prices if the merger was allowed unremedied? Notice the several significant steps as one moves from market share analysis to simulation. The process of constructing a simulation model provides a disciplined framework for the case team to implement an effects-based policy. It forces them to think deeply about the theory of harm and so identifies the relevant questions and data requirements. Much can be learned by taking these steps individually-in fact, much more than can be learned from each step than from a simple summary prediction, which is the standard bottom line of a merger simulation. The predictions from such models should be far less important than the process of getting there. In fact, the headline predictions can be an unfortunate distraction. ${ }^{40}$

Alongside this lack of a systematic approach to calibrating demand elasticities and cross-elasticities in general, full simulation models have begun to be used in the quantification of unilateral effects by both the merging parties and the Commission (for example, Volvo/Scania: see Ivaldi and Verboven 2005 and Hausman and Leonard 2005; also GE/Instrumentarium, for a simplified quantification). Such simulations were first used explicitly in a merger decision in Lagardere/Natexis/VUP, though the simulations appear to have been parachuted in. The simulation was of only a small part of the concerns of the merger and does not appear to have been decisive.

Nevertheless, this is a mighty bound-in analysis. Full-blown simulation can be a dangerous black box. As such, it is either believed uncritically or dismissed/ignored as black magic. This should not blind us to the virtues of going through the steps underlying a basic simulation, because this gives exactly the right information on which to base a good decision. If each of these steps can be verified as making sense in relation to the pattern of substitutability and pricing in a market, then it is natural to complete the simulation but still interpret the results with caution, particularly if, as is typical, the predictions are extrapolations into unobserved market structures and not interpolations within past experience. ${ }^{41}$ Nevertheless, it is important for an in-house expertise to develop in order to understand what can and what cannot be learned from simulations, and to have the ability to challenge external experts.

A quite separate criticism of full-blown merger simulations is that they are expensive and time-intensive. ${ }^{42}$ An alternative way to achieve a simple feel for the harm a merger may cause is to calibrate elasticities using expert opinions or surveys. This makes the methodology practicable and not excessively demanding in its data requirements. It is explicitly approximate and so makes it easier for non-experts to place in context. Davies and Lyons 2007 apply such 'basic 
simulation' techniques to a number of actual decisions for which the Commission required remedies. We show that for a series of paper and pharmaceuticals mergers, combined market shares range from around 20 per cent to 90 per cent, yet the predicted price rises are only loosely correlated with market share. In fact, we predict a price rise for the merger with the smallest market share and a possible decline for the merger with the largest market share. Clearly, the different elasticity estimates make a very significant difference, as do expected efficiencies. It must be admitted that some of these substitutability effects are implicit in the text of a decision, but the beauty of a basic simulation is that it allows the analyst to combine issues of substitutability and market share in an appropriate (though still approximate) way.

\section{EFFICIENCY DEFENCE}

Firms merge for many different reasons, including efficiencies, experimenting with product combinations and connections, family reasons, inappropriate managerial incentives, and hubris. Market power is another motive. Whether it is a deliberate motive or an incidental effect does not matter for merger control, but it is clear that it is not the only motive for merger. And, of all the other motives for merger, efficiency enhancement is economically the best (that is, for social welfare). In fact, in the absence of positive efficiency effects, it is hard to justify the much-less-hostile competition policy towards horizontal mergers in contrast to cartels.

In the early days of the ECMR, there were severe concerns by merging firms that the Commission was hostile to efficiency-enhancing mergers. The logic could be found in the idea of a DT-a merger that not only combines market shares but also forms an efficiency base for extending shares might appear to be doubly dominating. This view was given support by some early decisions (starting with AT\&T/NCR; Neven, Nuttall, and Seabright 1993). This fear of claiming efficiencies has become known as the efficiency offence.

The efficiency offence was meant to have been eliminated by the revised ECMR and Horizontal Merger Guidelines which came into force in May 2004. The new position, quite sensibly, is supposed to be that merger-specific efficiencies are a good thing, at least inasmuch as they reduce marginal costs because this tends to reduce price (or at least moderate any tendency for price to rise post-merger), which is beneficial to consumers. To this extent, there is now an official efficiency defence. ${ }^{43}$

Another perspective on the evolving change in emphasis is provided by looking at the annual reports of DG Comp. These suggest a slower change. Through the 1990s, the emphasis in the mission statement was on integration: Single European Market then European Economic and Monetary Union (EMU). Only very recently has efficiency become an explicit part of the mission statement: 
Competition Policy in the EU

The mission of the Directorate General for Competition is to enforce the competition rules of the Community Treaties, in order to ensure that competition in the EU market is not distorted and that markets operate as efficiently as possible, thereby contributing to the welfare of consumers and to the competitiveness of the European economy. ${ }^{44}$

Is there any evidence that the efficiency offence has been left behind and replaced by an efficiency defence? The words 'efficiency' or 'efficiencies' are not mentioned in DG Comp's Annual Report reflecting on 2004 (that is, the first following the revised ECMR and guidelines); there were plenty of mentions in 2005, but none in the section on mergers; and in 2006 there was a significant section reflecting on the efficiency defence in three mergers. ${ }^{45} \mathrm{In}$ Korsnäs/AD Cartonboard, the Commission accepted there would be efficiencies and that these would be significantly passed through, but only because of a term sheet agreement with a very strong buyer, Tetra-Pak. In Inco/Falconbridge, the Commission thought that the efficiencies could have been achieved without the merger and in any case were unlikely to be passed through to customers. In Metso/Aker Kvaerner, the Commission did not accept that the efficiencies would outweigh the anticompetitive effects. Overall, while these cases suggest there remains a high hurdle for firms to achieve an efficiency defence, it does seem that the efficiency offence may have been eliminated for horizontal mergers. ${ }^{46}$

There are several reasons why we may not observe firms offering an efficiency defence more often. First, it may be that mergers rarely achieve efficiencies that could not be attained by some other means. There is a paucity of academic evidence on merger-specific efficiencies, not least because it is difficult to measure the efficiency of mergers directly. The nearest proxies that can generally be measured are profitability and shareholder returns. Of course, these could include elements to reflect enhanced market power as well as reduced costs, but since only a very small fraction of all mergers are found to impede competition, we can at least draw some cautious implications about efficiency by studying a large enough sample of mergers. This evidence, summarized below in section 6.4.2., suggests that European mergers raise joint market value by around 1 per cent, which is consistent with rather modest efficiency gains. A further issue is that cost efficiencies only benefit consumers if they are passed through in lower prices. Again, there is remarkably little evidence on firm-specific cost pass-through (as distinct from industry-wide cost pass-through). The US case of Staples/Office Depot showed just 15 per cent firm-specific pass-through, thus requiring six or seven times the cost reductions compared with any enhanced-market-power price-raising effect (Ashenfelter, et al. 2006). ${ }^{47}$

Overall, while progress has been made in relation to the treatment of efficiencies in merger control, practice is still evolving and it appears that firms and their advisers remain cautious in deploying an efficiency defence. 


\subsubsection{Coordinated effects (collective dominance)}

\section{THE COMMISSION AND THE ECONOMICS}

There is a modern consensus on the economics of coordinated effects (see Ivaldi, et al. 2003b, or Motta 2005). This consensus is based on a canonical repeated game model of the sustainability of collusion. This has the following essential elements: (a) sufficient price transparency to identify deviations from coordinated behaviour; (b) lags in detecting and responding to such deviations; (c) the ability to impose a rational 'punishment strategy' on deviants; (d) discounting of future profit streams. The essential model is simple and powerful. It can be adapted to bring out numerous insights relating to, for example, market shares, number of firms, demand growth, product differentiation, cost asymmetries, and multi-market contact. It is such a neat model that adds credible punishment to more traditional transparency concerns. In thirty years, it rose from an abstract idea in game theory to the conventional wisdom implicitly accepted by the CFI in Airtours/First Choice in 2002. ${ }^{48}$ This is quite remarkable for a new idea in economics. ${ }^{49}$

Perhaps inevitably, there have been, and remain, a number of problems with the use of the canonical repeated game model. First, the model needs very careful adaptation to the individual circumstances of a merger, particularly in the presence of capacity constraints. This was not done in Nestlé/Perrier, where the importance of the distribution of capacities across firms was not properly appreciated at the remedies' stage (see Compte, Jenny, and Rey 2002). Another example is UPM/Kymmene/Haindl where the Commission published fairly implausible concerns over coordination in capacity expansion. However, to its credit, it did eventually listen to well-reasoned economic advice and accepted a carefully articulated theoretical and empirical argument that coordination would not be enhanced by this particular merger (see Kühn and van Reenen in Lyons 2009).

When carefully applied, the repeated game model is an excellent way of summarizing our current understanding of the sustainability of tacit coordination. However, there remains a serious gap in our understanding of how tacit coordination is initially achieved. In particular, the economists' canonical model is the same for explicit as for tacit collusion, yet the Commission regularly discovers that cartels with a dozen firms can be stable while, with the single exception of the overturned Airtours decision, it has never expected tacit coordination between more than two firms. This is quite consistent with the model which admits multiple equilibria (that is, even when coordination is sustainable, it will not necessarily be achieved because more competitive outcomes are always also sustainable). However, it does highlight that the model is silent on the process by which a coordinated price is achieved. The concern is not that the canonical repeated game model is wrong or misleading, but that it tells only half of the story of tacit collusion. It may be that this is an 
Competition Policy in the EU

area where sociology or organizational psychology can help. ${ }^{50}$ The point is that, following the Airtours decision, the Commission should neither ignore nor over-rely on the 'Airtours conditions'. They are necessary for the stability of coordinated effects but not sufficient for coordinated effects to actually emerge.

\section{THE COURT AND THE COMMISSION}

In this section, I investigate the influence of the Court on the Commission's attitude to coordinated effects, or collective dominance as this form of behaviour was known until 2004. In Table 6.2, I identify some landmark Commission and Court decisions. One very imperfect but simple way to 'measure' the importance attributed to coordinated effects by the Commission is to identify the number of merger decisions which non-trivially mention either collective dominance or coordinated effects. ${ }^{51}$ This information was collected by some of my colleagues for another purpose (Davies, Olczak, and Coles 2007). In Figure 6.1. I summarize these 'significant mentions' as a percentage of all decision, grouped in relation to those Table 6.2. landmark decisions that indicate significant changes in the direction of confidence of the Commission. ${ }^{52}$

The number of CD/CE 'significant mentions' in each period is not particularly large and there were events other than decisions by the Commission and CFI that will have been an influence. Also, the proportion of mergers genuinely causing coordinated effects may differ from year to year and will be endogenously determined by the deterrence effect of Commission decisions. Nevertheless, a rather interesting story of law and economics emerges.

- Early years of ECMR: the Commission did not consider collective dominance, but began to develop the idea of a strong second firm as a counterbalance to a merger creating or enhancing a leading market share.

- Nestlé/Perrier (1992): the possibility of collective dominance in merger cases becomes established, and this heralded a period of serious consideration of collective dominance. Gencor/Lonrho further raised the profile and even though Kali \& Salz was reversed in the Court, the principle of collective dominance in mergers was importantly confirmed.

- Airtours/First Choice (1999): emboldened by the earlier decisions and further success with the Gencor/Lonrho, confidence grew, including that ' 4 to 3' mergers might create collective dominance. During this period, there were seven cases where both single and collective dominance were found and remedies were required. ${ }^{53}$

- CFI strikes down A/F decision (2002): the shock of the Court reversals, particularly Airtours, brought about a period of retrenchment. While it seems that first phase decisions still considered collective dominance, there was much greater caution in Phase II 


\section{Merger Control: 1958-2007}

- Impala appeal against Sony/BMG clearance (2005): the CFI shocks the Commission in the opposite direction, opening up the possibility of coordinated effects in a ' 5 to 4 ' case. Commission responded with enormous caution in Phase II cases to ensure serious consideration of coordinated effects in nearly half of all Phase II cases. ${ }^{54}$

Table 6.2. Some landmark decisions in collective dominance/coordinated effects

\begin{tabular}{|c|c|c|c|c|}
\hline Case & Date of decision & Table 2 code & Decision & $\begin{array}{l}\text { Essential Case } \\
\text { Notes }\end{array}$ \\
\hline Nestlé/Perrier & 1992 & $N / P$ & $\begin{array}{l}\text { By Comm.: allow } \\
\text { s.t divestment }\end{array}$ & $\begin{array}{l}\text { ' } 3 \text { to } 2 \text { ' merger in } \\
\text { bottled water, with } \\
\text { 'remedy' creating } \\
\text { more equal market } \\
\text { shares }\end{array}$ \\
\hline Gencor/Lonrho & 1996 & $\mathrm{G} / \mathrm{L}$ & $\begin{array}{l}\text { By Comm.: } \\
\text { prohibition }\end{array}$ & $\begin{array}{l}\text { Would have been a } \\
\text { ' } 3 \text { to } 2 \text { ' merger in } \\
\text { two rare minerals; } \\
\text { first prohibition on } \\
\text { CD grounds }\end{array}$ \\
\hline Kali \& Salz & 1998 & & $\begin{array}{l}\text { By ECJ: quashed on } \\
\text { merits }\end{array}$ & $\begin{array}{l}\text { ECJ confirms } \\
\text { principle of } \\
\text { collective } \\
\text { dominance, but } \\
\text { not ' } 3 \text { to } 2 \text { ' when } \\
\text { merger would } \\
\text { create } 23 \% \text { share } \\
\text { and the ' } 2 \text { ' would } \\
\text { have a combined } \\
\text { share of } 60 \%\end{array}$ \\
\hline Gencor/Lonrho & 1999 & & $\begin{array}{l}\text { By CFI: upholds } \\
\text { prohibition }\end{array}$ & $\begin{array}{l}\text { Upholds principle } \\
\text { of CD due to } \\
\text { oligopolistic } \\
\text { interdependence } \\
\text { — structural links } \\
\text { unnecessary }\end{array}$ \\
\hline Airtours/First Choice & 1999 & $\mathrm{~A} / \mathrm{F}$ & $\begin{array}{l}\text { By Comm.: } \\
\text { prohibition }\end{array}$ & $\begin{array}{l}\text { Would have been a } \\
\text { ' } 4 \text { to } 3 \text { ' merger in } \\
\text { package holidays. }\end{array}$ \\
\hline A/F appeal in CFI & 2002 & $\mathrm{~A} / \mathrm{F}$ CFI & $\begin{array}{l}\text { By CFI: referred } \\
\text { back to } \\
\text { Commission for } \\
\text { proper analysis }\end{array}$ & $\begin{array}{l}\text { CFI severely } \\
\text { criticises } \\
\text { Commission } \\
\text { analysis. }\end{array}$ \\
\hline $\begin{array}{l}\text { Impala wins CFI appeal } \\
\text { over Sony/BMG clearance }\end{array}$ & 2006 & Impala CFI & $\begin{array}{l}\text { By CFI: referred } \\
\text { clearance back } \\
\text { to Commission for } \\
\text { proper analysis }\end{array}$ & $\begin{array}{l}\text { Proposal was a '5 to } \\
4 \text { ' merger in } \\
\text { recorded music. } \\
\text { Court criticises } \\
\text { Commission's } \\
\text { analysis of } \\
\text { transparency and } \\
\text { retaliation. } \\
\text { Commission } \\
\text { confirmed (in } \\
\text { 2007) its } 2004 \\
\text { clearance decision. }\end{array}$ \\
\hline
\end{tabular}


This analysis requires a particularly cautionary note for recent cases. The new substantive test was introduced in May $2004,{ }^{55}$ and this is likely to have changed how the Commission looks at non-leading mergers in the last period. For example, two 2006 decisions were prosecuted as non-coordinated effects while it is likely that the Commission would have felt it had to tackle these as collective dominance cases under the DT. T-Mobile/tele.ring (Phase II) would have created the second firm in the market with 30-40 per cent, behind Mobilkom with 35-45 per cent and with ONE as the third player with 15-25 per cent. There was also Linde/BOC (Phase I), in which three firms (including BOC) each had market shares of 25-40 per cent and Linde was an aggressive entrant. It is not clear whether it prosecuted them under non-coordinated effects because this is easier to prove (or at least less likely to fall foul of appeal) or whether the reform allowed the Commission to act on the theory of harm it genuinely believed.

Finally, I should be clear that a statistical analysis like that in Figure 6.1. says little about how good individual decisions were. Its purpose is to highlight trends that are missed by delving into individual case detail.

\subsubsection{Non-horizontal mergers}

The EAGCP (2006) ${ }^{5} 6$ subgroup set out five key principles as to why nonhorizontal mergers (NHMs) are different from horizontal mergers (HMs).

1) The competitive impact of NHMs is fundamentally different. HMs directly remove a competitor producing a substitute product. NHMs bring together complementary products and so may reduce competitive distortions (for example, double marginalization). The competitive effects are therefore entirely different.

2) The sources of competitive harm in NHMs often require a change in strategy and the impact on competition is indirect. While price rises can be expected for HMs in the absence of efficiencies or continuing competitive constraints, any adverse effects of NHMs require the introduction of a new strategy (for example, bundling). In order to find such a new strategy anticompetitive, it needs to be profitable and to harm competitors to the extent that their consumers are also hurt.

3) There are many forms of NHM so there is a large variety of ways in which different (competitive and anticompetitive) effects may occur. In fact, the canonical model of NHMs is the 'Chicago' view that there should be a presumption of benefits unless a carefully specified and specific harm can be proved.

4) Market power in an existing market is an essential prerequisite for competitive harm from foreclosure. In its absence, efficiency arguments should be presumed to prevail. 
5) There are stronger efficiency arguments for non-horizontal mergers than for horizontal mergers. NHMs are often motivated by the minimization of transaction costs in order to facilitate efficient coordination and specific investment, neither of which is a likely benefit in HMs.

One aspect of the Tetra Laval/Sidel appeal was that the CFI required a high standard of proof in cases of conglomerate and vertical effects. There is good economic justification for this in the following sense. Suppose that the standard of proof requires at least a 51 per cent chance/expectation of an impediment to competition in order to intervene (that is, prohibit or require remedy). In a horizontal case, there is essentially a single issue to prove-that rivals would provide a lesser competitive constraint than they do pre-merger. Nonhorizontal arguments are more complex and may require two or three essential steps in order to establish an expectation. If each step is essential, it is necessary to be more sure of each in order to reach the 51 per cent overall expectation of harm. For example, with two essential steps, each step would require an average of 72 per cent expectation on average $(0.72 \times 0.72=0.51)$ and, if three steps are essential, each would need 80 per cent expectation $(0.8 \times 0.8 \times 0.8=0.51)$.

Although non-horizontal mergers are far less frequently at issue than are horizontal mergers, there have been too many examples where these principles have been ignored. Controversy particularly surrounds so-called 'portfolio effects' which have been claimed to be anticompetitive due to the opportunity a conglomerate merger provides to bundle products purchased by the same consumers to the relative disadvantage of competitors. This is also the area which has caused most transatlantic disputes. The CFI has recently severely criticized two important Commission decisions invoking such effects (Tetra Laval/Sidel in 2002 and GE/Honeywell in 2005) but there was evidence of problems much earlier (for example, some of the analysis in Guinness/Grand Met, 1997). ${ }^{57}$

Worryingly, some of the problems with the analysis of conglomerate mergers seem to be stubbornly ingrained. For example, post the 2002 CFI decisions, merger reforms, and even CET, there is some poor reasoning in Lagardere/Natexis/VUP (Jan. 2004). This merger was allowed subject to remedies and there were probably sufficient horizontal issues to justify this. However, my concern is that efficiencies related to vertical and conglomerate aspects of the merger were discussed as highly problematic because they would harm competitors. These efficiencies include: efficient marketing and distribution; ease of moving from hardback to 'pocket book' format; higher advances to authors; and financial resources to allow long-term policies. Merger policy should not act against a publishing merger because the merged firm might be able to pay its authors more! The efficiency offence is as important to eliminate for non-horizontal as for horizontal mergers. 
Competition Policy in the EU

More careful analysis is essential, and the best way to enhance the accuracy and predictability of decisions is to provide clear guidelines. These cannot be as precise as for horizontal mergers because of the subtlety with which anticompetitive effects might manifest themselves. Nevertheless, case handlers, firms, and their advisers all need to know the parameters within which they operate. In view of the misconceptions, good guidelines are more important here than anywhere else. Guidelines for vertical and conglomerate mergers were promised 'during the course of 2004' (33rd Annual Report on Competition Policy 2003, \#223) but were held up first by the awaited appeal over GE/Honeywell (2005) and then by the abuse of dominance appeal by Microsoft (2007). They were finally agreed in late 2007.

There is no space for specific comment on the guidelines, but the EAGCP principles seem to have been appreciated and some appropriate procedures are set out. For example, in relation to foreclosure issues created by a merger, the Commission will establish: first, the enhanced ability to foreclose (that is, to reduce a rival's profits); second, the incentive to do so (that is, consequently to enhance the merged firm's profits); and third, whether a foreclosure strategy would have an anticompetitive effect downstream 'in ways that cause harm to consumers' (\#15) (that is, to raise price or otherwise harm consumers). ${ }^{58}$ This provides a strong structure for the analysis of non-horizontal mergers.

\subsubsection{Merger interventions and remedies}

\section{INTERVENTION TRENDS}

The top line in Figure 6.2. shows the trend in mergers decided by the Commission (right-hand scale). In order to avoid double counting, this trend is based on Phase I decisions. It shows the great merger boom at the turn of the century, with the number of mergers qualifying for scrutiny doubling between 1997 and 2000, followed by a dip then record numbers of qualifying mergers in 2006 and again in 2007. All other trends are measured on the left-hand scale. Four levels of intervention are identified: prohibitions are the most extreme but also least frequent; withdrawals during Phase II are often due to the parties deciding that their merger proposal was likely to be prohibited; more frequently, undertakings may be agreed short of prohibition (for example, divestitures) in order to eliminate the competitive harm in a proposed merger; and these undertakings, which are known as merger remedies, may be agreed early (that is, in Phase I) or late (that is, in Phase II).

In order to clarify the trends, Figure 6.3. expresses interventions relative to merger decisions and groups them into three periods. The first, 1990-7, can be thought of as a period of settling into the new regulation during a period with a steadily growing number of qualifying mergers, and finished with the first revision of the ECMR in 1997, which included a significant procedural changes 
affecting Phase I remedies. The next four years, 1998-2001, was a period of acceleration in mergers combined with growing confidence of the MTF. Thirdly, the most recent six-year period began with the Court reverses and Monti reforms.

Figure 6.3. includes two extra dimensions of intervention in addition to the four in the previous figure. First, a clearance in Phase II can be thought of as an intervention in that it imposes costs on a merger that might potentially have been cleared in Phase I. Second, some Phase I withdrawals may be due to the parties anticipating that their merger proposal would be referred to Phase II. ${ }^{59}$ These 'softer' categories of intervention are separated by a solid line in the figure. In general, Figure 6.3. arranges interventions with the strongest (that is, prohibitions) and the bottom and the weakest at the top of each column.

Prohibitions are on trend decline. They peaked with five prohibitions in 2001 (that is, one-quarter of all prohibitions in just one year), three of which were subject to major appeals in the Court, ${ }^{60}$ since when there has been just two prohibitions. ${ }^{61}$ However, adding withdrawals in Phase II and remedy decisions changes the picture. The intervention rate rose from 7.5 per cent in the first period, to10.8 per cent during the confident turn-of-the-century period, before falling to 6.4 per cent. Adopting the broader concept of intervention (that is, including Phase II clearances and Phase I withdrawals) presents a similar trend with the exception that Phase I withdrawals have been

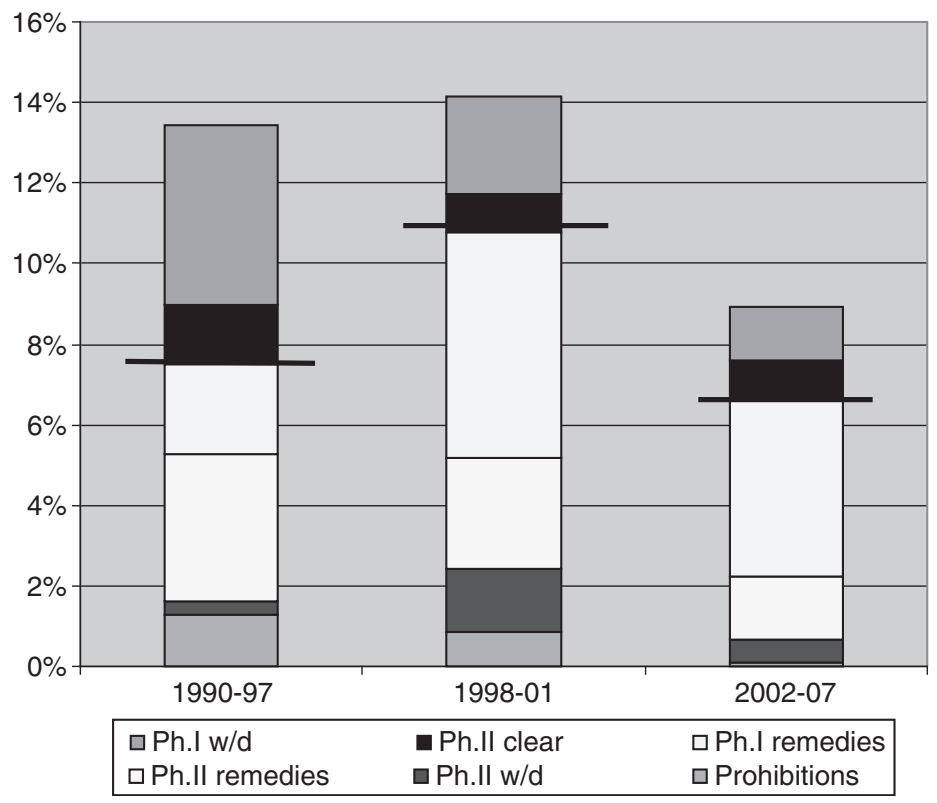

Figure 6.3. Intervention rate 
Competition Policy in the EU

declining steadily over the years. The high rate of Phase I withdrawals in the first period may have been a learning effect on the part of firms who did not properly appreciate the implications of the ECMR in its early years. Finally, two other trends are not so readily discerned from the figure: the Phase II referral rate has halved from 7 per cent to 6 per cent to 3.5 per cent over the three periods; and the ratio of remedies to prohibitions has grown very rapidly from 5 to 10 to $53 .^{62}$

Overall, there appear to be three overlaying trends, the first two being monotonic over time and the third not so. First, more is being agreed in Phase I and less referred to Phase II. Second, more mergers are being remedied as opposed to prohibited. Third, the peak of intervention in1998-2001 has seen a very substantial reversal in recent years.

\section{EFFICACY OF REMEDIES}

It is clearly important that agreed remedies should be effective in restoring competition that would otherwise be impeded by a merger. In 2005, DG Comp completed its own in-house study of past merger remedies. The study analysed forty decisions containing ninety-six different remedies, adopted by the Commission between 1996 and 2000. These cases were sampled to pick up on a range of alternative remedies and different industrial sectors, as well as Phase I and Phase II agreements. The study used interviews with the parties selling and purchasing divested assets and with trustees. They carried out a total of 145 full interviews.

In terms of the design and implementation of divestitures, the most frequent problem was insufficient scope of assets transferred such that the business could not stand alone from its previous parents. This afflicted 80 per cent of the divestitures and one-third of the problems remained unresolved after three to five years. Carve-out of assets from a previously integrated business was mentioned as a problem about half as much. Transfer issues and inadequate interim preservation of assets pending transfer were the next most frequent problems, together afflicting up to two-thirds of divestitures though most such problems were resolved in three to five years. The unavailability of a suitable purchaser was problematic in around one in five cases. Moving away from divestitures, there was limited evidence on access and other non-divestment remedies. The sample was small, but three out of four infrastructure remedies failed due to the market developing very differently from what had been anticipated. Technology access agreements were often flawed due to the licensor being able to limit transfer of essential support technology. Overall, the fundamental difficulty of setting suitable access terms was the single most important element impeding access as an effective remedy.

Combining the above findings with a limited number of market indicators such as market share, the study was able to provide a basic assessment of the 
effectiveness of remedies. On the simple criterion of whether divested assets were still in business three to five years later, the DG Comp study found that 6 per cent were not (7 per cent of which had been transferred to new ownership). ${ }^{63}$ Only 18 per cent of divested businesses increased market share, with one-third remaining the same. Compared with the market share performance of assets retained by the merging parties, only 23 per cent of divestitures did better, with 57 per cent doing worse. The Commission's own assessment was that, 57 per cent of divestitures were considered effective, 24 per cent partially effective, 7 per cent ineffective, and 12 per cent unclear. Access remedies were least effective.

In Davies and Lyons 2007, we were able to analyse the competitive consequences of remedies applied to some mergers in more depth. Our research drew on both detailed interviews from the DG Comp study and our own modelling of the remedied markets. Most of the mergers we looked at were between firms with multiple market overlaps, and nearly all of the remedies involved what we call 'prohibition within the market'. In other words, once a trigger threshold of impediment to competition is assessed to have been reached, one or other of the merging parties' businesses was required to be divested in its entirety. One of our key findings was that the restoration of market structure does not necessarily mean the restoration of competition. While the Commission took care to ensure that buyers were suitably established firms, it did not necessarily take other important issues into accountfor example, the incentives to market and develop products when brand ownership is split across geographic markets due to selective divestiture.

At the time of writing, the Commission is consulting on draft revised remedy guidelines. These generally improve remedy practice. However, there are four issues on which the Notice could be improved. The first two relate to remedy selection and the second two to implementation.

First, licensing agreements in remedies have used terms like 'adequate compensation' and 'normal and non-discriminatory commercial conditions'. These terms are open to abuse leading to ineffective remedies. Much clearer guidance is necessary to determine commercial terms and licence duration such that competition will be fully restored.

Secondly, our research revealed a significant minority of cases where there is a national geographic market and where the anticompetitive overlap is very small. In such cases, some form of price and production commitment would almost certainly have been the better option to divestiture. This seems to be particularly the case where the merger has numerous product and geographic markets and the parties may be so keen to get the main part of the merger approved that they propose a divestiture when that is not in their customers' best interests (for example, there is no buyer with a serious interest in a small product, even though they can be tempted by an appropriately low purchase price). We suggest the Commission should be much more willing to accept 
Competition Policy in the EU

behavioural guarantees when: the market is very small; there is a significant risk that potential purchasers of a divestiture will not invest in the product; and where the identity of customers makes it sufficiently easy for them to monitor undertakings.

Thirdly, at the time of negotiations between the merging parties and a potential purchaser of divested assets, the seller and buyer will agree a deal that maximizes their joint profits. The distribution of such profits will be reflected in the purchase price. Joint profits will normally be maximized by a purchaser who does not intend to use the assets to compete directly with the merging parties. There is, therefore, a serious danger that a seller and purchaser collude to avoid the restoration of competition to the pre-merger level (Farrell 2003). In this context, we welcome the proposal that the Commission proposes to discuss business plans with potential purchasers. However, the Commission should take steps to ensure that these plans are credible and that they do restore competition.

Fourthly, two weaknesses in relation to trustees are not sufficiently addressed in the new draft. First, the merging firms both propose the trustee and determine the mandate, albeit with the approval of the Commission. My concern is not one of explicit bias, but of the failure of the Commission to be the first to instruct the trustee on the reason for the divestiture. In the past, many have not been aware of the competition concerns, let alone the requirements necessary to restore competition. Indeed, this is typically not their expertise. Second, trustees are paid by the merging parties. Combined with being appointed and instructed by them, this sets in stream a natural loyalty to the merging firms and to their shareholders. This holds even when the trustee is an experienced auditor. Therefore, in addition to being the first to instruct a new trustee, it would be better if the Commission or some third party could pay them and claim back costs from the firms.

\subsection{Merger Policy Evaluation}

How efficient is the Commission in reaching merger decisions? Recent 'peer review' type league tables place it close to the best in the world ${ }^{64}$ Although little reliance can be put on such beauty shows, it does establish that the Commission is doing a reasonably good job by international standards. This is all the more impressive in that it is not particularly generously resourced. Nevertheless, as I have already argued, it could do significantly better.

In the following section, I propose a very simple summary measure of the efficiency of EC merger control based on elementary bargaining theory. In a second section, I review some recent statistical evaluations based on shareholder value and changes in response to Commission decisions. 


\subsubsection{A bargaining failure approach to inefficient merger control}

The first principle of bargaining theory is that, in the absence of asymmetric information, if there is a mutually beneficial deal to be done, it will be agreed. ${ }^{65}$ The details of who gets what depends on bargaining power, particularly relative costs of delay and outside options. In the presence of asymmetric information, mistakes will be made in that negotiations break down but this should be infrequent if there is an effective information-gathering process. The second principle is that the deal should be reached very quickly. Delay imposes a deadweight loss during which the beneficial agreement is not implemented, in addition to which there are direct compliance and investigation costs of Phase II. ${ }^{66}$

In the context of merger appraisal, bargaining theory suggests that an efficient system should be able to

- reach a deal between the agency and the merging parties; and

- reach it reasonably quickly (that is, more often in Phase I than in Phase II).

Breakdown in negotiations can be manifested in either a prohibition or the parties walking away. A prohibition arises either if the Commission is unduly harsh, or if the merging parties made a mistake in proposing an irredeemably uncompetitive merger or in offering an insufficient remedy for a potentially

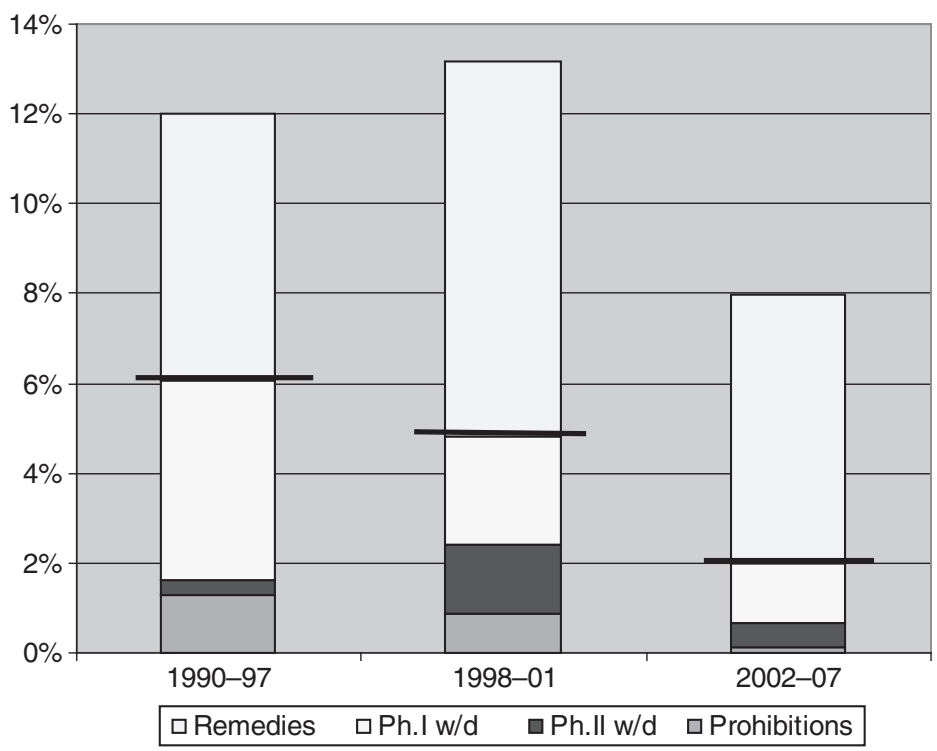

Figure 6.4. Failure to agree 
Competition Policy in the EU

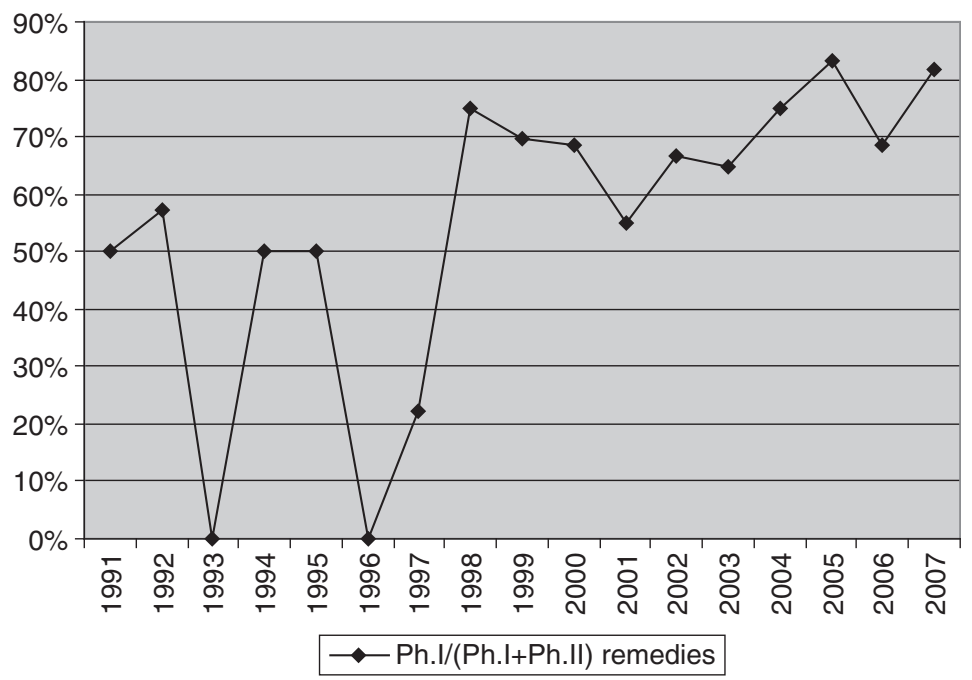

Figure 6.5. Speed of agreement

beneficial merger. Either way, all prohibitions are mistakes by one side or the other, even though it is not possible to attribute blame for such mistakes. Unilateral withdrawals by the merger parties are a little more complex. In particular, withdrawal may be due to outside reasons like a change in market conditions. Nevertheless, some will be due to the expectation, developed during the investigation, that the agency will not agree with what the merger parties believe would be an acceptable deal.

Figure 6.4. shows the trend in merger decisions against failures to agree, along with remedy agreements for context. To avoid double counting of Phase II, the baseline trend is again represented by the number of Phase I decisions. First look at the total number of failures to agree defined as prohibitions plus withdrawals in either phase (that is, the columns below the bar). This shows a trend improvement in reaching agreement, suggesting an increasing efficiency of communications between merging firms and the Commission. Reasons for this include experience, more written guidance, a more economic approach, and the impact of the Courts. In relation to the last of these it certainly seems significant that there was a zero failure to agree in 2003 (that is, in the year that followed the three great reverses to the Commission in 2002!). Looking at the components of the failures to agree, Phase I withdrawals are always the largest contributor, but they are also probably the most influenced by external factors. More interesting is that prohibitions generally outweighed Phase II withdrawals until 1997, since when the reverse has been true. ${ }^{67}$ 
The main measurable dimension of speedy agreement is remedies agreed in Phase I as compared with Phase II. This trend is shown in Figure 6.5. There is a significant legal reason for the distinct change in the pattern from 1998 because the 1997 amendment to the ECMR clarified the legal position of remedies agreed in Phase $\mathrm{I}^{68}$ In the former period, more remedy agreements were achieved in Phase II than in Phase I, and only 38 per cent were not subject to these costly delays. In contrast, the last decade has seen an improved efficiency such that 69 per cent are agreed in Phase I (1998-2006). Needless to say, the efficiency interpretation of this crude analysis must be taken with a very large health warning. ${ }^{69}$ Apart from the revision to the ECMR, it is quite possible that more mistakes are made in Phase I remedies than in Phase II. Nevertheless, it does seem that negotiating efficiency has improved. It takes both sides to reach agreement, so the credit for this must be shared between the merging firms (or their advisers) and the Commission.

Putting together the reducing failure-to-agree rate and the early-agreement rate, we can reconsider to the positive deterrence effect of the ECMR-the hidden benefits of merger regulation in deterring harmful mergers from being proposed in the first place. If firms completely ignored the ECMR when making merger proposals, we would expect a large number of anticompetitive mergers to be proposed, with a consequently large number of prohibitions. We do not observe this, so the true benefits of the ECMR are grossly underestimated by looking only at actual mergers. Firms act with foresight and take account of the prospect of the merger control when making proposals.

Overall, this very simple bargaining approach is consistent with a more positive deterrence effect in the last decade, but little continuing improvement. This may be because some sort of optimum has been reached, or it may be that the Monti reforms will take a little longer to be absorbed into rational expectations.

\subsubsection{Other statistical evaluation approaches}

The event study framework, discussed in section 6.2.3. above, can be developed to estimate the effectiveness of competition policy. Duso, Neven, and Röller 2007 and Neven and Röller 2002 use the Eckbo 1983 methodology which focuses on the share price response of competitor firms. The argument is that if they can expect to benefit from a reduction of competition in the market, then their valuation will rise; but if the merger is expected to create a fierce or efficient new competitor, then their valuation will fall. For horizontal mergers, the effect on rivals is, in theory, a sharp indicator of whether a competition agency should intervene in a merger or not. ${ }^{70}$ In practice, stockmarket valuations are likely to be very imprecise as an indicator of competitive effects. Even professional investors may need time to identify the extent of overlap markets and evaluate complex competitive impacts. Effects will also be 
Competition Policy in the EU

reduced to the extent that they build the anticipated regulatory response into their valuations. ${ }^{71}$ The authors look at all Phase II mergers up to 2001 and a randomly matched sample of Phase I cases. Competitors were identified from the decisions. Weighted average CAR gains for the merging parties are again around 1 per cent and they find just over half of mergers are pro-competitive judged by competitor impact. They found that four out of fourteen prohibitions in their sample were wrong (type 1 error) judged by competitor impact (these include the appealed Airtours/First Choice, Tetra Laval/Sidel, and GE/ Honeywell). The Commission also made type 2 errors by clearing one-quarter of anticompetitive mergers without remedy. Thus, there was a roughly equal balance of type 1 and type 2 errors. They also found no United States effect but weak evidence for more excessive intervention on firms from small countries and insufficient intervention for national and EU markets (compared with a global relevant market). However, their strongest result was that many more errors are made in Phase I decisions. They conclude: 'The probability of waving an anticompetitive merger through [in phase I] is some 75 per cent higher, which is a high price to pay. This suggests that allocating more time and resources to phase I, as well as opening phase II more frequently, may reduce type II errors considerably. ${ }^{, 72}$ A similar caution against Phase I agreements in complex mergers can also be found in the pharmaceuticals case studies in Davies and Lyons 2007.

Aktas, de Bodt, and Roll 2007 estimate a 'probability of intervention' equation to supplement their stockmarket impact analysis. Based on a sample of EU mergers 1990-2000 they find that foreign acquirers are subject to more frequent 'regulatory intervention' than domestic acquirers, but only when local EU competitors are 'being harmed'. They define regulatory intervention as either Phase I remedies or referral to Phase II, so clearance in Phase II is included as an intervention. 'Being harmed' means a decline in CARs around the merger event window. They conclude that the Commission has been operating a protectionist policy, intervening disproportionately when EU firms expect to lose out to a more efficient competitor. There are some substantial problems with this study, not least in the very broad interpretation of the competitor set (not taken from decisions) and in the absence of variables to reflect the degree of overlap in competition-relevant markets or market shares. Nevertheless, it provides food for thought. ${ }^{73}$ Note that both the Duso, Neven, and Röller 2007 and Aktas, de Bodt, and Roll 2007 studies were based on pre2002 mergers and so exclude mergers since the Monti reforms.

Other econometric studies have used information from within published decisions to investigate the market structural determinants of an intervention. Without the supplement of stockmarket valuations, such studies can only investigate the consistency of decisions-they have no independent estimate of whether decisions are right. Lindsay, Lecchi, and Williams 2003 examine 245 mergers decided 2000-2 and finds, not surprisingly, that high market 
shares and barriers to entry are the main determinants of an adverse decision. ${ }^{74}$ They also look for nationality effects, but find neither US nor Nordic ownership mattered. Bergman, Jakobsson, and Razo 2005 separate the decision to go to Phase II from the conditional decision to prohibit, given Phase II. Market share is important for both, particularly for the Phase II decision. The only other significant variable for prohibition is if the firm was a world leader. Entry barriers and fears of coordination are significant for Phase II referral. No effect was found to do with individual commissioners or firms from large EU Member States, but US firms were less likely to be referred to Phase II.

Davies, Olczak, and Coles 2007 focuses on collective dominance cases prior to 2004. They develop an econometric model of Commission decisions to find that, although the combined market share of the largest two firms has a similar quantitative effect on an adverse finding, size symmetry (measured by the ratio of the share of the second firm to that of the largest) has a negative effect on a finding of single dominance but a positive effect on a finding of collective dominance. These effects are statistically highly significant which suggests that the Commission is at least selecting between unilateral or coordinated effects in more or less appropriate configurations of market shares.

\subsection{Conclusions}

Actual decisions are only the tip of the iceberg in terms of the impact of merger control, because these decisions along with guidelines and policy pronouncements influence the type of mergers that firms propose. Given the costs of delay and compliance, firms a have considerable incentive to propose mergers that will be acceptable. This makes it crucial to publish the right argument behind a decision. If this guidance is sufficiently clear and if firms rationally anticipate merger control, they will only propose acceptable or marginally harmful mergers-this is why Phase II merger control is, or should be, very difficult to call. In this sense, the analysis is more important than the decision itself.

The right analysis is based on the expected economic effects of a proposed merger. Competition economics is an evolving discipline and has made major progress in the second half of the fifty years under review. Although many ideas are now well established, this does mean that some of the economics is relatively new and it is not surprising that some earlier decisions were not as good as they might have been.

When the ECMR was introduced in 1989, the Commission (DG IV) had a reputation for slow decision-making. The new MTF was legally required to act speedily and it achieved this. The evidence suggests it grew a little careless during the turn-of-the century merger boom and this reinforced the Monti reform package. Institutional reforms within the Commission (for example, 
Competition Policy in the EU

'fresh pair of eyes', chief economist's team) have improved merger control and the Court has, on the whole, been a positive influence. Reform of the ECMR and the provision of guidelines have also been important and certainly positive.

Turning to the substantive analysis used by the Commission, the analysis of non-coordinated effects is becoming more receptive to efficiencies, but there is still work to be done in implementing the publicly stated policy. Also, the Commission has yet to clarify its attitude to highly sophisticated economic analysis, in particular to merger simulation. Simulation has both benefits and limitations and it should proceed cautiously. It needs to avoid relying on a 'black box' grinding out price predictions, but it should utilize the steps underlying simulation (for example, estimation of cross-elasticities) to gain a more accurate understanding of the market.

The Commission has had an interesting relationship with the Court in relation to coordinated effects, and there is evidence that it may have swung too far in response to each new decision. Nevertheless, the revised substantive test and recent Airtours decision should encourage it to analyse mergers in the way it genuinely believes they may cause harm. Bearing in mind the 'iceberg effect' of decisions on merger proposals, it is more important to make the right argument than to live in fear of being overturned on appeal.

Commission practice on non-horizontal merger appraisal has been the weakest part of its analysis. This has been recognized by the Court, but there continue to be worrying signs in some recent decisions. The new guidelines are long overdue and urgently needed.

The efficacy of merger remedies has received considerable attention recently, and this research will no doubt improve future practice. Divestitures have too often been insufficient to establish a competitive, as distinct from simply viable, business, and licensing remedies are often rendered ineffective because insufficient attention is paid to specifying the terms of a licence. Furthermore, the Commission should not be shy of simple behavioural remedies in cases where small, typically national, markets are involved. These could save transaction and incentive costs associated with small divestments while ensuring a better outcome for consumers. More generally, the Commission should become more proactive with divestiture trustees and buyers to ensure there is no collusion or neglect in running down the assets.

Finally, we considered some wider evaluations of EC merger policy. Clear anticipation of merger control should lead to fewer anticompetitive mergers being proposed (so fewer prohibitions) and quicker agreement of remedies. The early years of the ECMR are consistent with a period of learning which mergers are, and which are not, acceptable. This process almost certainly applied to both the Commission and merging firms. Separate event study evidence is consistent with both type 1 and type 2 decision errors being made by the Commission. Such studies and other case study evidence also 
caution against the presumption that Phase I remedies are necessarily more efficient than agreements in Phase II as they suggest that more mistakes are made in the former.

Overall, the Commission's merger regime is maturing fairly well. It has shown itself to be capable of self-criticism and able to reform. It has established a good reputation, recovered from a difficult time with the Court in 2002, and is well positioned to improve further-but there is still work to be done and no room for complacency.

\section{Notes}

1 An earlier version of this chapter was prepared for the IESE conference 'Fifty Years of the Treaty: Assessment and Perspectives of Competition Policy in Europe', held in Barcelona, 19-20 Nov. 2007. <http://www.iese.edu/en/events/spsp/50years_2007/ 50years2007.asp $>$. The support of the Economic and Social Research Council is gratefully acknowledged. Many thanks also for helpful comments from Michael Harker, KaiUwe Kuhn, Carles Esteva-Mosso and Xavier Vives, none of whom is responsible for the views expressed in this chapter.

${ }^{2}$ If we include Phase II withdrawals, the intervention rate is 8.8 per cent. See sect. C. 1 for further discussion of withdrawals.

${ }^{3}$ Note that the UK system does not require notification and it is possible that this may affect the comparability of these figures.

${ }^{4}$ The report also suggests a number of other reasons why there will be a greater 'below the water' effect than these figures suggest. It also provides that the negative deterrence (or 'business chilling') effect is limited to small beneficial mergers withdrawing rather than facing the costs of a Phase II investigation by the Competition Commission.

5 Although the economic approach is sometimes thought to reduce the legal certainty obtained by applying rigid rules, this certainty would come at the expense of sensible decisions. Nevertheless, there is a role for 'safe harbours' as a way of limiting the fear of intervention when market shares are sufficiently small.

${ }^{6}$ Explicit merger control in the competence of the European Commission was only introduced in 1989 so the main focus of the chapter is on the period since then. The starting date in the title is, therefore, a little misleading because most of the chapter is about only the last third of the period.

7 See Gerber 1998.

${ }^{8}$ It is worth noting that Luce and Raiffa's classic early textbook on game theory was published in 1957, but this approach was still far removed from practical competition policy. It is only with hindsight that we can note its importance.

${ }^{9}$ Of course, this is a somewhat heroic generalization. Other lines of thought, including transaction cost economics and the emerging field of behavioural IO, are important influences, and there are a few national differences, but these do not detract from the general conclusion that recent generations of industrial economists draw on essentially the same toolkit for their understanding of competition issues.

10 The same is probably true of the law and legal precedent. 
Competition Policy in the EU

${ }^{11}$ Kohl was the new boy keen to build a reputation by acting on the European stage, Mitterrand was looking for something to distract attention from a doomed domestic macroeconomic policy that had been humiliated by international financial markets, and Thatcher had finally found something European she could support after years of obstructionism.

12 Of course, there were many other influences behind this merger wave, which was also happening in the USA. See sect. A. 3 below.

13 Political influence is thus more subtle than in the US Department of Justice which has political appointees.

${ }^{14}$ Even under the expedited procedure, the CFI judgments have taken twelve months beyond the initial Commission Decisions, which themselves were five to six months after original notification of the merger proposals. Few merger proposals are resurrectable after such a period. In the absence of the expedited procedure, the appeal takes much longer. For example, Airtours/First Choice took just under three years from Commission decision to CFI judgment; and from notification of merger to CFI judgment took nearly five years in GE/Honeywell.

15 In the United States, the Department of Justice and Federal Trade Commission (whichever is given responsibility for a particular merger) combine stages 1 and 2 (i.e. second request), before presenting their case to the court for a preliminary injunction (i.e. decision). In practice, most cases are settled before going to court, but the immediacy of the courts has a major impact and discipline.

${ }^{16}$ Notwithstanding this focus on judicial review, the CFI has shown itself willing to engage in some serious economics, as in Airtours/First Choice.

17 For example, the Commission's protracted dispute with Spain since 2005 over Gas Natural/Endesa and EON/Endesa.

18 The Clayton Act prohibits any acquisition, the effect of which 'may be substantially to lessen competition, or to tend to create a monopoly' (Clayton Act \#7, 1914).

19 Some examples of apparently rigid market share rules used by the Commission in relation to pharmaceuticals mergers are given in Davies and Lyons (2007), for example, in ch. 8.

${ }^{20}$ Economic advice accounted for some 15 per cent of merger-control-related feessimilar to the split in the USA, but still leaving lawyers with the lion's share!

21 Schneider/Legrand and Tetra Laval/Sidel both came through the new expedited procedure.

22 See Garces, Neven, and Seabright 2009 for a discussion of this case.

23 DG Comp immediately appealed to the European Court of Justice fearing some of these issues could undermine merger control. The appeal was rejected in Feb. 2005.

${ }^{24}$ See Vives and Staffiero 2009 for a discussion of this case.

${ }^{25}$ For completeness, and to anticipate that not everything has been solved by the reforms about to be discussed, in 2006 a third-party appeal over a 2004 clearance was upheld (i.e. referred back to DG Comp, who did more analysis and cleared it again in 2007). Impala over Sony/BMG: inadequate assessment of potential coordinated effects.

26 It began in 2003 with ten PhD-level economists and in 2007 planned to grow towards twenty members. See Röller and Buigues 2005 for more detail on the CCE and CET.

27 I put 'new' in inverted commas because the essential change was to reverse the ordering of a sentence. The 2004 revision of Article 2.3 of the ECMR reads in full: 
'A concentration which would significantly impede effective competition, in the common market or in a substantial part of it, in particular as a result of the creation or strengthening of a dominant position, shall be declared incompatible with the common market.' This compares with the 1989 original: 'A concentration which creates or strengthens a dominant position as a result of which effective competition would be significantly impeded in the common market or in a substantial part of it shall be declared incompatible with the common market.' Nevertheless, this remains an important signal of priorities, not least in the common shorthand of SIEC compared with DT.

${ }^{28}$ Kuhn 2002 disagrees that a revised substantive test for the ECMR was necessary.

29 The following paragraphs are based on a submission I made in response to the public consultation on the 2001 Green Paper and in which I argued that a SIEC test should be adopted.

30 Recital 25 of the revised ECMR clarifies that filling this gap is an aim of the new test.

31 An official data series on 'Acquisitions and Mergers of Industrial and Commercial Companies' started in 1967. Unlike the later merger waves, many of the UK mergers at this time were driven by diversification.

32 As Symeonidis 2000 shows, the consequent increase in competition was slowly eroded by an increase in concentration over the next twenty years. Other studies (e.g. Prais 1981 and Hannah and Kay 1981) attribute a disputed proportion of the increase in concentration at that time to mergers.

33 See also Ilzkovitz and Meiklejohn 2006: ch. 1 and Martynova and Renneboog 2008a; 2008b.

34 Another feature of international mergers is that they can bring new ideas in corporate governance. See, for example, Bris, Brisley, and Cabolis 2008, Martynova and Renneboog 2008b, and Burkhart and Berglof 2003.

35 In Lyons 2001 I argue that this pattern of findings is consistent with mergers being a response to anticipated adverse market conditions and does not necessarily mean that they are 'unsuccessful'.

${ }^{36}$ Lyons 2009 includes six excellent case studies of mergers and merger appraisal in Europe.

37 The Commission does not adjust market shares for an expected contraction of output post merger, which is a necessary condition for harm to consumers (Farrell and Shapiro 1990). The 50 per cent figure is consistent with the ECJ in an Article 82 case, Akzo 1993, where it is taken to establish dominance in the absence of exceptional circumstances. Other Article 82 appeal cases accept a share closer to 40 per cent and occasionally lower. Merger findings of dominance have tended to use similar thresholds (see Whish 2003: chs. 5 and 21).

${ }^{38}$ However, in the early years of the ECMR, the Commission made the mistake of forgetting that the same benefits of a strong rival are not relevant if coordinated effects are at issue-in fact, quite the opposite (e.g. Nestlé/Perrier).

39 Some implicit discussion of these concepts is often found under 'market definition'. A closely related concept to elasticity and cross-elasticity is the diversion ratio, which if often a more intuitive way of getting at the same thing.

40 See the case studies of merger simulations by Slade and by Gollier and Ivaldi in Lyons 2009. 
Competition Policy in the EU

41 Slade (in Lyons 2008) provides an incisive critique of the sensitivity of simulations to often arbitrary technical assumptions.

42 Though sophisticated simulations can sometimes be achieved within the constraints of a merger inquiry (e.g. Ivaldi in Lyons 2008).

${ }^{43}$ I have no space to go into the important issue of whether this defence should be on the basis of a consumer welfare standard, as implied here, or a total welfare standard, such that even if consumers lose out a little this can be more than compensated for by enhanced profits (i.e. the famous 'Williamson trade-off'). I favour the consumer welfare standard for mergers because this is more likely to encourage positive deterrence and the self-selection of beneficial mergers by firms (see Lyons 2002; Farrell and Katz 2007). Fixed-cost savings would become important under a total welfare standard.

44 DG Comp 2007 Annual Management Plan: 4 (emphasis added). The italicized text on efficiency was first added only in 2006.

45 The 2007 report was not available at the time of writing.

46 Sadly, the same may not yet be true of non-horizontal mergers. See below.

47 Stennek and Verboven provide another example in Ilzkovitz and Meiklejohn 2006, but they rather implausibly estimate greater than 100 per cent pass-through of costs, which is hardly likely for cost reductions. Another possibility is it that firms are still scared to claim efficiencies. Unpublished research currently under way at the CCP by Peter Ormosi looks at what merging firms report to their shareholders as compared with what is said about merger-specific efficiencies in a merger decision. He finds that firms report much more positive cost savings in annual reports than is reported in decisions. While there may be some reporting bias if evidence is presented by firms but not reported in a Commission decision, he argues that firms still prefer to offer remedies in Phase I rather than risk a costly Phase II investigation in the hope of a successful efficiency defence.

48 The germ of the idea can be traced back to Luce and Raiffa 1957 but was applied seriously to the abstract theory of tacit collusion only in the 1970s (starting with Friedman 1971, and culminating in Abreu's work in the mid-1980s). The model is not mentioned in sixty-five pages devoted to coordination in Scherer 1970. Important applied theoretical and econometric work during the 1980s (Rotemberg and Saloner; Green and Porter; Porter; Slade) soon established its value, and it is central to Tirole's (1988) treatment of tacit collusion, and remains so in Motta 2005.

49 New ideas need academic testing both for theoretical robustness and on real world data. Once properly understood, the knowledge must be transferred to practitioners (through recruitment of recent graduates who have learnt the new ideas, commissioning of review papers, and conferences) who must feel confident enough to apply the knowledge. Finally, the judges must find the ideas sufficiently intuitive and compelling to be accepted by the court.

50 See e.g. Scott Morton 1997 for an influence on cartels.

51 Or joint dominance or oligopolistic dominance or tacit collusion.

52 Apart from the first period (1990-1), there were between 762 and 1,031 Phase I and between 24 and 58 Phase II decisions in each period in Fig. 6.1.

53 Garces, Neven, Seabright 2009 provides a good discussion of the importance of this case for the analysis of collective dominance/coordinated effects.

54 In fact, most of the jump was in 2006, where two-thirds of Phase II cases seriously considered CE. This had dropped back to one quarter in 2007. However, there were only 
a small number of decisions in each of these years (twelve each). There is apparently a surprising drop in Phase I analysis, but this may be due to a change in the method used for Phase I cases (data since 2004 is subject to revision).

55 Hence, the change of terminology from CD to CE.

56 The Economic Advisory Group on Competition Policy provides independent academic advice to the European Commission. The author was one of the subgroup members drafting this advice.

57 See the chapters by Stenbacka and Vives and Staffiero in Lyons 2009 for critiques of cases involving vertical and conglomerate effects.

${ }^{58}$ It is positive to observe that the Commission's success in the Microsoft appeal in relation to exclusionary effects has not diluted the draft guidelines.

59 And so incur compliance costs and the risk of prohibition or deal-breaking remedy requirements. Other reasons for withdrawal include changes in stock market conditions and adverse responses by shareholders.

60 Tetra Laval/Sidel, Schneider/Legrand, and GE/Honeywell.

$61 \mathrm{ENI} / \mathrm{EDP} / \mathrm{GDP}$, which would have brought together the very dominant gas and electricity suppliers in Portugal. There is also the 2007 prohibition of Ryanair/Aer Lingus.

${ }^{62}$ There is no obvious change in the nature of proposed mergers that would explain these trends.

${ }^{63}$ On this minimal criterion, European merger remedies appear to have been more successful than in the USA, where an earlier FTC study suggested a much smaller survival rate. However, the comparison is unfair because Europe was able to learn from the US experience. It is also the case that exit generally is slower in Europe than in the USA.

${ }^{64}$ Every three or four years, the UK government conducts an independent peer review of national and international authorities, mainly by lawyers but also consulting competition economists and firms. For the merger regime in 2007, the EC ranked fourth behind the USA, UK, and Germany. Relative to the USA, it scored 94 per cent in 2001, falling to 86 per cent in 2003/4, before recovering to 91 per cent in 2007. Global Competition Review conducts an annual survey of competition lawyers and in their mergers survey DG Comp has risen to joint first place alongside the FTC and UK Competition Commission.

65 With symmetric ignorance, both parties may wish to gather information so that they can be more sure that a mutually beneficial deal exists.

${ }^{66}$ A study of fifty companies involved in over 500 mergers worldwide, conducted by PricewaterhouseCoopers (PwC) and jointly commissioned by the International Bar Association and American Bar Association, found a typical cost for the firms of 3.3 million for a cross-border merger even when scrutinized by a single authority.

67 The one exception in the last decade was in 2001 when an exceptional five mergers were prohibited (three of which were significantly reversed in the CFI).

${ }^{68}$ See revision to Art. 6(1) in Council Regulation (EC) No 1310/97 of 30 June 1997 amending Regulation (EEC) No 4064/89 on the control of concentrations between undertakings (OJ L 180, 9.7.1997: 1-6). A change in the 2004 revisions to the ECMR may also have had some effect because it no longer requires firms to notify one week after the conclusion of the deal. However, the earlier rule was not often respected and the suspension provides sufficient incentives to ensure that firms normally notify without excessive delays. I am grateful for Carles Esteva-Mosso's opinion that this change has not had a significant impact in remedy negotiation. First, it is uncommon that companies 
Competition Policy in the EU

are ready to start negotiating remedies in pre-notification. Second, even before the 2004 modification, the Commission was happy to discuss remedies in pre-notification (e.g. Unilever/Bestfoods). As ever, they engage in discussions without prejudice of the results of Phase I investigation. If new concerns arise during the investigation or during 'market testing', parties could be required to improve the remedies.

${ }^{69}$ Garrod, Lyons, and Medvedev 2008 provide more sophisticated econometric investigation of the speed of agreement and link this with the type of error to be expected (i.e. whether agreements are too tough or too soft).

70 Only where the merger is expected to lead to exclusionary effects (in nonhorizontal mergers) would a decline in rival value be associated with anticompetitive effects.

${ }^{71}$ Some UK and US studies have looked at the stock market response at each stage of merger investigation in order to trace the impact of new information, but the results tend to be rather noisy. See Beverley 2008 and references therein.

72 See also Duso, Neven, and Röller 2007 and Duso, Gugler, and Yurtoglu 2006b for a similar analysis of merger remedies.

${ }^{73}$ See also Aktas, de Bodt, and R. Roll 2004.

${ }^{74}$ However, the mention of entry barriers in a decision may not be an independent measure as it could be mentioned or not in order to bolster a decision based on other factors. 